\title{
Library Materials: \\ Paper, Microform, Database
}

\section{Michael K. Buckland}

Electronic publications and machine-readable databases have characteristics that do not "fit" library practice well. For technical and historical reasons, using databases differs from using paper or microform library materials. The characteristics of all three media are examined and compared as a basis for a more unified approach, with special reference to research libraries.

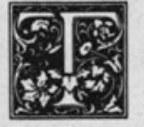

he growth of databases of bibliographical and numerical information is obvious. The need to provide access to these forms of information as part of a research library's mission is clear. Further, we can expect a rapid growth of textual information and of images in machine-readable form that ought also be made available. ${ }^{1}$

Libraries evolved to provide access to information from collections on paper-or in other media resembling paper. Library patrons also need access to information in machine-readable form (databases). Databases' characteristics differ from those of paper and do not fit well into current library practice. For example:

1. Special equipment is required to use databases;

2. A library can provide database service without the user or the database located in the library. Usage need not be restricted to the library's open hours and library staff may not be at hand to offer assistance; and

3. Databases customarily involve costs based on the amount of use, making expenditures difficult to project or to control.

How can these difficulties be addressed in a way that will optimize the users' access to information and increase the li- braries' flexibility in adapting to change?

This paper explores the characteristics of library materials and considers some of the assumptions about library provision that have been built on the basis of collections on paper. ${ }^{2}$

\section{CHARACTERISTICS OF LIBRARY MATERIALS ON PAPER}

Library materials on paper have characteristics that are familiar to librarians and library users:

1. No special equipment is needed to read them;

2. They are strictly localized. The reader must read a printed book, pamphlet, map, or journal where that item is: the reader must go to the book, or the book must be physically transported to the reader. Possibly another copy can be acquired or made, but each copy would still have to be where its reader is. Any given copy may only be read by one person at a time and in the one place where that copy is located. Obvious though this may seem, it is an important constraint in library planning because the use of information is highly sensitive to location: a book at hand is used more than a book on the other side of campus, let alone on another campus or in an-

Michael K. Buckland is Professor, School of Library and Information Studies, University of California, Berkeley, California 94720. 
other state. As a result, expenditure for the selective duplication of library materials in different libraries on the same campus is generally needed, and there is at least mild contention for unduplicated material of interest to two or three groups at different locations. The size of locally held collections is taken to be the measure of the worth of the library. ${ }^{3}$

3. Information on paper does not lend itself to simultaneous viewing by two or more people. Either another copy must be found (or made) or users must take turns.

4. Library materials on paper are treated as a capital, public good: they are bought and made available without charge. They are bought at a one-time cost as an investment, the cost is not passed on to the reader, and, until the copy becomes worn-out, no additional cost (other than circulation and reshelving work load) is involved in it being read by one more person. If demand exceeds supply, three options exist: rationing use by limiting loan privileges, increasing supply by adding another copy, or lowering the standard of service by letting additional would-be readers wait. ${ }^{4}$

5. Formulas have been developed to indicate adequacy of provision of paperbased materials according to the number and nature of academic programs. ${ }^{5}$

Library activities, and especially library budgetary practices, are based on these characteristics.

\section{CHARACTERISTICS OF MICROFORMS}

The first major programs of microfilming library materials began with newspapers in the 1930s. Use of microforms increased greatly in the 1960 s as microfiche were used for the dissemination of technical reports by government agencies. ${ }^{6} \mathrm{Mi}-$ crofilms and other microforms represent a significant departure from paper materials, yet differ on only one of the five characteristics noted above-special equipment is needed to read them. This required libraries to maintain a new sort of equipment: microform readers and printers. Microforms are, therefore, even more localized than paper materials: not only must the would-be reader and the microform be in the same place, but there must also be a machine to read it on. Further, copies are less convenient to make and cannot, like paper, be annotated. Nevertheless, the low cost of acquiring and storing microforms makes them a reasonable choice for some sorts of information (such as old newspapers) in spite of their unappealing form and other attributes.

\section{CHARACTERISTICS OF DATABASES}

Machine-readable databases, as typically used in library contexts, differ from paper not on just one of the five characteristics of paper-based materials, like microforms, but on all five:

1. As with microforms, special equipment is required to read themequipment that is substantially more complex, more expensive, more useful, and more obsolescent than microform readers. Not only is the equipment providing access to databases more elaborate than microform equipment, but it has two other novel features. First, a microfilm reader displays an image but does little else, except, perhaps, produce a copy. Computers used in conjunction with databases not only allow retrieval but also a great deal of manipulation: bibliographical data can be reorganized, reformatted, and combined with other machine-readable text; texts can be edited and stored again in revised form; and numerical data, such as census tables, can be retrieved and subjected to statistical manipulation. (A census table on paper or microform would have to be transcribed by hand and/or keyed into machine-readable form.) Secondly, the equipment used to gain access to databases is usable for other purposes. A scholar's personal computer can be used for word processing, electronic mail, statistical analysis, and manipulation of personal databases as well as accessing external databases. Moreover, a convenient linking of each of these functions allows data to flow conveniently between them.

2. Database usage is not inherently localized. For example, thousands of people all over the world use the databases made available through the Lockheed DIALOG 
service, but few of these people have ever been to Palo Alto where the databases reside. There is a strong trend for at least faculty and graduate students to have workstations, either terminals or microcomputers, enabling them to read databases from their offices, laboratories, and homes as an alternative to using workstations in libraries. Databases can be copied, and scholars will probably tend to have their own copies of parts or all of some databases, even though, given telecommuni-

\section{"... it does not matter to an online searcher where the data on the screen come from, so long as they too arrive in a timely and reliable manner."}

cations, databases can be used and shared from a distance. In this sense, databases lend themselves to cooperative, shared provision much better than do library materials on paper or microform. Just as it does not matter to a library user where an interlibrary loan book has come from, so long as it arrives in a timely and reliable manner, it does not matter to an online searcher where the data on the screen come from, so long as they too arrive in a timely and reliable manner. (Possible cost differences may matter to the librarian but that is a separate issue.)

3. Given suitable equipment, users of databases can, in effect, make simultaneous use of the same database, whereas it is not practical to make simultaneous use of the same book. Contention for the same book is a major source of frustration for the library user.?
4. Databases have, in general, not been budgeted as a capital, public good. Typically, databases have been provided on a pay-as-you-use fee basis, including telecommunications, computer charges, and other elements. These expenses-real, monetary charges-are passed on to the users, except to the extent that libraries feel able to absorb them. These charges had no real precedent in library budgets. This situation is reflected in the common practice of referring to bibliographical databases as "commercial databases," even though it is the final stage of retail marketing, not the data, that has been in commercial pay-as-you-use mode.

5. Bases for determining and justifying budgetary provision are less established for use of databases than for materials on paper. Some databases contain new material and, therefore, add to the library's collection; others duplicate paper materials and so could at least partially substitute for print; distance-independence makes shared provision more practical; changing electronic technology, e.g., the introduction of databases on CD-ROMs, continually increases the options; future levels of demand are unknown; and future pricing practices of database publishers are unclear. Budget projections are difficult to make.

These characteristics of library materials on paper, in microform, and as machinereadable data files are summarized in table 1.

\section{SOME ASSUMPTIONS RECONSIDERED}

Because access to information on databases is a desirable part of the mission of a library and yet does not fit existing practices, it may be useful to retreat toward first principles.

TABLE 1

COMPARISON OF LIBRARY MATERIALS' ATTRIBUTES IN DIFFERENT MEDIA

\begin{tabular}{lccc}
\hline \hline & Paper & Microform & Database \\
\hline 1. Equipment required & No & Yes & Yes \\
2. Remotely accessible & No & No & Yes \\
3. Simultaneous use & No & No & Yes \\
4. Capital, public good & Yes & Yes & No, but could be \\
5. Basis for budgeting & Yes & Yes & Not yet developed \\
\hline
\end{tabular}


Why are library materials acquired in the first place? They are acquired to provide access to useful information in them. This does not signify that buying and retaining them is the only way to go. Consider three ways to provide access:

1 . Buying the material and retaining it so long as it is believed to be potentially useful;

2. Subscribing to it, in the sense of a flat subscription or rental fee for unlimited use for a given period of time; and

3. Pay-as-you-use fee for access.

Is it possible to use subscriptions or fees for paper-based materials? Precedents for rental are few in traditional library provision. Public libraries commonly rent collections of best-sellers to take care of temporary peaks of demand. In a few cases, reference works, e.g., Magazine Index and certain Dun \& Bradstreet directories, are available to libraries on a lease basis only, not for purchase. The library makes an annual payment. The publisher supplies and updates the reference work. Yet if the library stopped paying, the reference work would be returnable to the publisher. However, these arrangements, though reasonable in special cases, are not characteristic of research libraries where the difficulty of predicting future needs leads to an emphasis on acquiring many different titles and retaining at least one copy indefinitely.

Fee-based library services for paper library materials are even less evident since the concept of the free library replaced subscription libraries. Arguably there are two exceptions. Users ordinarily pay to make copies of library materials. It would be consistent with the mission of the library to supply photocopies without charge, but this is done only sparingly. Meeting readers' needs through interlibrary loan involves a use-based cost to the library, though this, too, is not ordinarily passed on to the user. Budgets being inevitably limited, reliance on interlibrary loan is reasonable and inevitable for materials that are expensive to acquire and least likely to be used.

We conclude that rental or fee-for-use is not excluded on theoretical grounds even for paper materials, but, rather, the cir- cumstances in which they would make sense hardly arise in research libraries, except for photocopies (where the cost is passed on to the user), interlibrary loan (where the cost usually is not passed on), and some reference works (where the library, but not the user, pays on a lease basis).

The conclusion that the reasons for preferring to purchase library materials on paper are practical (rather than based on the inherent properties of the material) provides a basis for reconsidering databases:

1. The purpose of making printed books, microforms, and databases available is the same: to provide access to potentially useful information. It would, therefore, seem sensible to budget for databases in the same way as is already done with paper and microform materials-if feasible.

2. There is no obvious reason why databases could not be purchased, unless the publisher chose not to sell them as a matter of marketing policy. It seems reasonable to expect that most databases will become available for purchase. Some, indeed, may be published on CD-ROM disks inexpensively enough for individuals to purchase copies.

3. Similarly, databases may also be available on a rental or subscription basis. This would be a matter of the university renting the database or negotiating access to it for a fixed fee and allowing users to make what use of it they can.

4. Fee-for-use access to databases would still be needed in two cases: when the publisher refuses to allow any other arrangement, and when usage or, more exactly, the cost, is so low that purchase or subscription is not worthwhile. (This is comparable to reliance on interlibrary loan of paper and microform materials in lieu of purchase.) It does not follow that the fee would necessarily have to be passed on to the user. Indeed, some cases of very low usage might well be handled by coordinated acquisitions of databases between universities and reciprocal search access, in the historic tradition of cooperative collection development.

5. The economic trade-off between pur- 
chase, lease, and usage-based fees will be largely a matter of technical analysis of the varying costs of computing, telecommunications, administration, and storage. Optimization of this sort would become even more practical if all systems seemed similar to the user, as they would with the general adoption of a "linked systems protocol," 'based on NISO draft standard Z39.50, for connecting online bibliographical systems. ${ }^{8}$

Although access to databases has been dominated by the commercial, fee-for-use provision such as that of Lockheed DIALOG and other retailers, it should be noted that database publishers are usually not the same as the retailers who provide access. Many useful databases are published by federal agencies (ERIC, Medline) or by scholarly or professional societies (Chemical Abstracts, Mathematical Reviews). Even where the publishers are also the retailers, it may well be in the publishers' interests to sell or rent copies of their databases directly to libraries or usersregardless of how much use will be made of them-in addition to arranging for feebased usage. For example, the Medline and ERIC databases can both be bought. Libraries are currently paying for the paper edition and also for use-based online searching fees. If a version of the database can be purchased and made available internally for unlimited searching, it might be an acceptable and worthwhile substitution for both paper and fee-based usage.

"... we should expect and plan for the nationwide preoccupation with the retrospective conversion of cata$\log$ records to be followed by a second wave of retrospective conversion of the contents of the cataloged objects."

Supplying databases to libraries would probably greatly increase database usage (and database owner's income) compared with provision on a fee-for-use basis only.
It is at this point that the distanceindependent characteristic of databases becomes important. Depending upon assumptions about telecommunications and levels of demand, one copy anywhere on a campus, multicampus system, or consortium might suffice for all users in a way that would not have the disadvantages that remote storage has for material on paper or on microfilm.

On this approach it is not difficult to imagine a hierarchy of levels of access to databases. Very popular, inexpensive ones might be held at a campus, or even branch library, level; less popular, more expensive ones might be held at a university level; yet other rarely used databases might be held regionally by universities or commercial services and used as needed, rather like interlibrary loans.

For paper materials not held in a library's collection, recourse is made to interlibrary loan. While this is not the same as doing a fee-for-use search of a remote database, the effect is quite similar. A nontrivial cost is incurred by the borrowing library for each interlibrary loan transaction. This is inevitable partly because no library can afford to buy everything. It is, however, a sensible strategy to avoid purchase, processing, and storage costs of some materials not expected to be much used and to plan on recourse to interlibrary loan if demands arise. ${ }^{9}$ With either paper materials or databases, as the level of usage increases, other approaches (purchase or lease) deserve consideration.

\section{SOME PRACTICAL IMPLICATIONS}

The above discussion would seem to indicate some practical actions:

1. "Library materials" and "Library materials fund" should be viewed as including machine-readable data files, whether for purchase, for rental, or for accessing files neither purchased nor rented. Whether or not the resources are adequate is an important, but separate, issue. ${ }^{10}$

2. Libraries should seek to arrange alternatives to the traditional fee-for-use basis. These options include purchase; rental; access by subscription, i.e., a flat 
fee for the use of databases not held locally; and collaborative mutual resource sharing of databases with other institutions.

3. Although present discussion tends to focus on bibliographical and numerical databases, other text and image databases are being developed. Indeed, we should expect and plan for the nationwide preoccupation with the retrospective conversion of catalog records to be followed by a second wave of retrospective conversion of the contents of the cataloged objects.

4. Many practical arrangements for handling databases need to be developed: storage, compatible computing support (hardware and software), telecommunications, copyright, security, documentation, archiving, preservation, and user support.

5. The adequacy of the budgetary rationale for library materials, including those that are formula-based, needs to be reconsidered so that machine-readable materials can be incorporated.

Databases are an important and growing medium. If libraries do not play a leading role in providing access to them, then a part of the libraries' role will be abnegated. For libraries not to provide access would be like a fifteenth-century library refusing to acquire the newfangled printed books in addition to manuscripts because they did not fit the library's practices. Databases do not fit library practices, but that is not the real problem. Databases are part of the evolving world of communication and of scholarship. The real problem is that current library practices have not yet changed sufficiently to fit that world. Machine-readable databases pose a challenge of adaptation for libraries if they are to continue in the mold of Ashurbanipal's enduring archetype. ${ }^{11}$

\section{REFERENCES AND NOTES}

1. Frederick G. Kilgour, Beyond Bibliography (London: British Library, 1985).

2. See Joanne R. Euster, "Changing Views of Library Collections," Library Issues 6, no.5:1-2 (May 1986).

3. Michael K. Buckland, "Concepts of Library Goodness," Canadian Library Journal 39, no.2:63-66 (Apr. 1982).

4. See Michael K. Buckland, Book Availability and the Library User (New York: Pergamon, 1975).

5. Melvin J. Voigt, "Acquisition Rates in University Libraries," College and University Libraries 36, no.4:236-71 (July 1975).

6. Convenient introductions can be found in: ALA World Encyclopedia of Library and Information Sciences (Chicago: American Library Assn., 1980), s.v. Micrographics, p.370-73 and Encyclopedia of Library and Information Science, v.18 (New York: Dekker, 1976), s.v. Microform, p.76-99 and Microform publication, p.99-114.

7. Buckland, Book Availability.

8. Michael K. Buckland and Clifford A. Lynch, "The Linked Systems Protocol and the Future of Bibliographical Networks and Systems," Information Technology \& Libraries 6, no.2:83-88 (June 1987); Michael K. Buckland and Clifford A. Lynch, "National and International Implications of the Linked Systems Protocol for Online Bibliographical Systems," Cataloging and Classification Quarterly (Forthcoming).

9. See, for example, Gary S. Lawrence and Anne R. Oja, An Economic Criterion for Housing and Disposing of Library Materials, Based on Frequency of Circulation (Berkeley: Univ. of California, Library Studies and Research Division, Sept. 24, 1979), Research Report RR-79-2.

10. See Jay M. Poole and Gloriana St. Clair, "Funding Online Services from the Materials Budget," College \& Research Libraries 47, no.3:225-29 (May 1986); followed by "Reactions" by Sheila Dowd, John H. Whaley, and Marcia Pankake, p.230-37.

11. Peter Briscoe and others, "Ashurbanipal's Enduring Archetype: Thoughts on the Library's Role in the Future," College \& Research Libraries 47, no.2:121-26 (Mar. 1986). 